$$
\text { CoNF-9706179--1 }
$$

\title{
PHOTOSYNTHETIC HYDROGEN AND OXYGEN PRODUCTION BY GREEN ALGAE
}

\author{
E. Greenbaum and J. W. Lee \\ Oak Ridge National Laboratory* \\ P. O. Box 2008
}

Oak Ridge, TN 37831

\begin{abstract}
Submitted for Publication in the
Proceedings of the International Conference on Biological Hydrogen Production

BioHydrogen ' 97
\end{abstract}

June 23-26, 1997

Waikoloa, HI

Keywords: Photosystem I, Photosystem II, reaction center, stoichiometric ratios, saturating flash yields, hydrogen, oxygen, chlorophyll antenna size, Z-scheme, mutants, Chlamydomonas, energy conversion efficiency, hydrogenase, oxygen sensitivity

DISTRBUTION OF THIS DOCAMENT IS UNLANTED
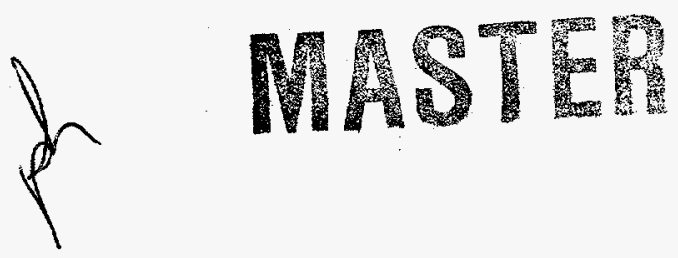

\footnotetext{
*Managed by Lockheed Martin Energy Research Corp., for the U.S. Department of Energy under contract DE-AC05-96OR22464.
} 


\section{DISCLAIMER}

This report was prepared as an account of work sponsored by an agency of the United States Government. Neither the United States Government nor any agency thereof, nor any of their employees, makes any warranty, express or implied, or assumes any legal liability or responsibility for the accuracy, completeness, or usefulness of any information, apparatus, product, or process disclosed, or represents that its use would not infringe privately owned rights. Reference herein to any specific commercial product, process, or service by trade name, trademark, manufacturer, or otherwise does not necessarily constitute or imply its endorsement, recommendation, or favoring by the United States Government or any agency thereof. The views and opinions of authors expressed herein do not necessarily state or reflect those of the United States Government or any agency thereof. 


\section{DISCLAIMER}

Portions of this document may be illegible electronic image products. Images are produced from the best available original document. 


\section{Summary}

An overview of photosynthetic hydrogen and oxygen production by green algae in the context of its potential as a renewable chemical feed stock and energy carrier is presented. Beginning with its discovery by Gaffron and Rubin in 1942, motivated by curiosity-driven laboratory research, studies were initiated in the early 1970 s that focused on photosynthetic hydrogen production from an applied perspective. From a scientific and technical point of view, current research is focused on optimizing net thermodynamic conversion efficiencies represented by the Gibbs Free Energy of molecular hydrogen. The key research questions of maximizing hydrogen and oxygen production by light-activated water splitting in green algae are (1) removing the oxygen sensitivity of algal hydrogenases; (2) linearizing the light saturation curves of photosynthesis throughout the entire range of terrestrial solar irradiance - including the role of bicarbonate and carbon dioxide in optimization of photosynthetic electron transport and (3) the minimum number of light reactions that are required to split water to elemental hydrogen and oxygen. Each of these research topics is being actively addressed by the photobiological hydrogen research community. 


\section{Introduction}

Photosynthetic hydrogen production by green algae was discovered in the pioneering experiments of Gaffron and Rubin (1942). This work was followed up by Gaffron and his colleagues in a series of seminal papers (Gaffron, 1960; Kaltwasser et al.,1969; Stuart and Gaffron, $1971 \& 1972 ;$ ) as well as many others. From the point of view of renewable fuels and chemical feedstock production, it is light-activated simultaneous photoproduction of hydrogen and oxygen that is of primary interest. The pioneering experiments in this field were performed by Spruit (1958) who developed a novel two-electrode polarographic technique for the simultaneous measurement of hydrogen and oxygen transients by the green alga Chlorella. The principle conclusion he came to was that hydrogen and oxygen metabolisms are closely related and they derived from water splitting. Later work by Bishop and Gaffron (1963) indicated that light-dependent evolution of hydrogen appeared to require both photosystems.

Research on photosynthetic hydrogen production as a renewable energy source began in the 1970s (Gibbs, et al., 1973; Lien and San Pietro, 1975, Mitsui et al., 1977). Using the twoelectrode technique Bishop et al. (1977) measured and interpreted hydrogen and oxygen production from a large group of green algae. However, due to the buildup of hydrogen and oxygen, with subsequent inhibition (vide infra) these reactions could be followed for only several minutes. Using a flow system that removed inhibitory oxygen, it was shown (Greenbaum, 1980) that sustained simultaneous photoproduction of hydrogen and oxygen could be observed for hours. In prior experiments using a glucose-glucose oxidase trap, Benemann et al. (1973) demonstrated hydrogen production from water by a chloroplast-ferredoxin-hydrogenase system. Measurement of the hydrogen analog of the Emerson and Arnold photosynthetic unit size (Greenbaum, 1977a, b) indicated that photogenerated reductant expressed as molecular hydrogen 
was derived from the mainstream of the photosynthetic electron transport chain. Direct measurement of the turnover time of photosynthetic hydrogen production (Greenbaum, 1979 and 1982) demonstrated that this parameter was comparable to the turnover time of oxygen production. It was also shown (Greenbaum, 1988) that net conversion efficiencies of 5-10\% could be achieved in the linear low-intensity region of the light saturation curve.

\section{The Three Problems}

Fig. 1 is a schematic illustration of the minimum number of components required for lightactivated hydrogen and oxygen production in green algae. The hydrogenase enzyme is synthesized de novo under anaerobic conditions. In normal photosynthesis carbon dioxide is the preferred electron acceptor for photogenerated reductant from Photosystem I. However, direct kinetic competition between hydrogen evolution and the Calvin cycle can easily be observed (Graves et al. 1989; Cinco et al. 1993). The three scientific research problems associated with photosynthetic hydrogen and oxygen production are (1) oxygen sensitivity of hydrogenase; (2) antenna size, bicarbonate and the light saturation problem; and (3) the minimum number of light reactions required to split water to molecular hydrogen and oxygen.

\section{Oxygen Sensitivity of Hydrogenase}

In the application of intact unicellular green algae for hydrogen production one is confronted with the problem of oxygen sensitivity of the hydrogenase enzyme. Hydrogenase is synthesized under anaerobic conditions and, at present, must be kept that way in order to preserve its functionality. As illustrated in Fig. 1 oxygen and hydrogen by green algae are coproduced in the same volume. Therefore, a way must be found to prevent inhibition of 
hydrogenase activity by the photosynthetically produced oxygen. This challenging problem is the focus of research at the National Renewable Energy Laboratory (Ghirardi et al., 1997) and is reported elsewhere in these proceedings.

\section{Antenna Size, Bicarbonate and the Light Saturation Problem}

Schematic illustrations of the relationship of the light saturation curves of photosynthesis and the light-harvesting antennas to the photosynthetic electron transport chains are presented in Figs. 2 and 3. In full sunlight, $\approx 1000 \mathrm{~W} / \mathrm{m}^{2}$, there exists a kinetic imbalance between the rate of photon excitation of the reaction centers and the ability of the thermally-activated electron transport chains to process photogenerated electrons. Whereas the reaction centers can receive photoexcitations at the rate of $\approx 2000 \mathrm{sec}^{-1}$, movement through the electron transport chain is of the order of $200 \mathrm{sec}^{-1}$ or less (Gibbs et al., 1973). Therefore, normal photosynthesis saturates at much less that full sunlight, typically $\approx 10 \%$. This is illustrated in the lower parametric curve of Fig. 2 labeled 200:1 implying 200 chlorophylls per reaction center. The actual number varies, of course, depending on alga and growth conditions. (Melis, 1989, Melis et al., 1996) This is the situation that is illustrated schematically on the left-hand side of Fig. 3 where 200 chlorophylls service a single reaction center.

Since there is little opportunity to increase the rate of thermally-activated electrons through the photosynthetic electron transport chain, an alternate strategy is illustrated in the righthand side of Fig. 3. Kinetic balance between the rate of photon excitation and rate of photosynthetic electrons can, in principle, be balanced, even at full sunlight, by reducing the absolute antenna size per reaction center. Under optimum conditions the idealized response is linear, illustrated by the parametric curve labeled 20:1. If such a response could be achieved in a 
real-world system, photosynthetic productivity on a per chlorophyll basis would increase and high solar irradiances would be converted to useful biomass energy. Linearization of the light saturation curve of photosynthesis was demonstrated by Herron and Mauzerall (1972). Melis et al. (1998) have demonstrated linearization of the light saturation curve for high-light grown cultures of Dunaliella. These results indicate that the concept is technically correct.

An additional complication of the light saturation problem involves the requirement of bicarbonate to optimize electron transport through Photosystem II. Since carbon dioxide/bicarbonate are the exclusive sink for photosynthetically generated reductant they need to be removed so that the flow of electrons produces hydrogen rather than carbon dioxide fixation compounds. Complete removal of carbon dioxide, however, impairs electron transport in Photosystem II and further reduces the saturating light intensity for sustained simultaneous photoproduction of hydrogen and oxygen by about factor of 10 . Qualitatively speaking, light saturation occurs at about $10 \mathrm{~W} / \mathrm{m}^{2}$. One strategy to overcome this limitation is to take advantage of the differential affinity of $\mathrm{CO}_{2}$ /bicarbonate between the Photosystem II binding site and the Calvin cycle. Such an approach has been explored by Cinco et al. (1993) in which light-activated hydrogen and oxygen evolution as a function of $\mathrm{CO}_{2}$ concentration in helium were measured for the unicellular green alga Chlamydomonas reinhardtii. The concentrations were $58,30,0.8$ and $0 \mathrm{ppm} \mathrm{CO}_{2}$. The objective of these experiments was to study the differential affinity of $\mathrm{CO}_{2} / \mathrm{HCO}_{3}{ }^{-}$for their respective Photosystem II and Calvin cycle binding sites vis-à-vis photoevolution of molecular oxygen and the competitive pathways of hydrogen photoevolution and $\mathrm{CO}_{2}$ photoassimilation. The maximum rate of hydrogen evolution occurred at $0.8 \mathrm{ppm} \mathrm{CO}_{2}$. The key result of this work was that the rate of photosynthetic hydrogen evolution can be increased, at least partially, by satisfying the Photosystem $I I \mathrm{CO}_{2} / \mathrm{HCO}_{3}^{-}$binding site requirement 
without fully activating the Calvin-Benson $\mathrm{CO}_{2}$ reduction pathway. These preliminary experiments suggest that mutants of Chlamydomonas reinhardtii that have a genetically engineered low $\mathrm{CO}_{2}$ affinity for the Calvin cycle and relatively higher affinity for the PS II $\mathrm{CO}_{2} / \mathrm{HCO}_{3}^{-}$binding site may be good candidates to explore for relieving the $\mathrm{CO}_{2}$ part of the light saturation constraint.

\section{The Minimum Number of Light Reactions}

It has recently been reported (Greenbaum et al., 1995; Lee et al., 1996) that mutants of the green alga Chlamydomonas reinhardtii that lack detectable levels of the Photosystem I (PS I) reaction center are capable of sustained simultaneous photoevolution of $\mathrm{H}_{2}$ and $\mathrm{O}_{2}, \mathrm{CO}_{2}$ reduction and photoautrophic growth. The data indicated that under some circumstances PS II alone is sufficient to generate reductant capable of driving hydrogen evolution and $\mathrm{CO}_{2}$ fixation, not of course that the Z-scheme is universally wrong. Although the absence of PS I in mutants B4 and F8 for the data reported in the references was confirmed by physical, biochemical and genetic techniques, subsequent analyses in our own laboratories as well as those of colleagues to whom we have sent the mutants indicate that there is variability in the PS I content of the cultures depending on growth conditions. While some strains retain undetectable levels of P700, others contain variable $(0-20 \%)$ amounts of wild-type P700. This property of mutants B4 and F8 has been communicated to the journals in which the results were initially published (Greenbaum et al. 1997a). The fact that mutants B4 and F8 can synthesize fluctuating levels of PS I raises the possibility that small amounts of this reaction center might exclusively generate reductant that can drive hydrogen evolution and carbon dioxide fixation.

In his analysis of this work, Boichenko (1996) postulated a "leaky" model of the Z- 
scheme, illustrated schematically in Fig. 4. According to this model, under continuous highintensity light PS I turns over with sufficient rapidity to accommodate reductant generated by multiple PS IIs thereby preserving a key requirement of the Z-scheme: Only PS I is capable of generating low-potential reductant that can be used for hydrogen evolution or carbon dioxide fixation. Based on comparative rates of photosynthesis with wild-type Chlamydomonas reinhardtii and known (Melis et al., 1996) properties of PS I antenna size it was felt that the earlier results were not consistent with this model even if PS I were present, but undetectable. Preliminary data (Greenbaum et al. 1997b), testing the leaky Z-scheme model of Fig. 4 on direct measurement of absolute single-turnover saturating flash yields of hydrogen and oxygen production in mutant Fud26 as well as photosynthesis measurements under light-limiting conditions $\left(\mathrm{O}_{2}\right.$ evolution with $\mathrm{CO}_{2}$ as electron acceptor) $)$ suggest that the leaky $Z$-scheme model cannot quantitatively account for the measured amounts of photosynthesis. Therefore, in addition to the Z-scheme the pathway, there is, in mutant Fud26, an alternative oxygenic photosynthetic pathway.

\section{Acknowledgments}

The authors thank L. J. Mets, T. G. Owens, A. Melis, K. Redding, I. Vassieliev and J. Golbeck for collaboration, advice, and discussion of this work. They also thank C. V. Tevault and S. L. Blankinship for technical support and L. Wagner for secretarial support. This research was supported by the U.S. Department of Energy. Oak Ridge National Laboratory is managed by Lockheed Martin Energy Research Corp. for the U.S. Department of Energy under contract DEAC05-96OR22464. 


\section{References}

Bishop NI and Gaffron H (1963) On the interrelation of the mechanisms for oxygen and hydrogen evolution in adapted algae. In Photosynthetic Mechanisms in Green Plants, B. Kok and A. T. Jagendorf, Eds. (Natl. Acad. Sci.-Natl. Res. Council, Washington, DC), pp. 441-451.

Bishop NI, Fricke M, and Jones LW (1977) Photohydrogen production in green algae: water serves as the primary substrate for hydrogen and oxygen production. In Biological Solar Energy Production, A. Mitsui, S. Miyachi, A. San Pietro, and S. Tamura, Eds. (Academic Press, New York) pp. 1-22.

Boichenko VA (1996) Can photosystem II be a photogenerator of low potential reductant for $\mathrm{CO}_{2}$ fixation and $\mathrm{H}_{2}$ photoevolution? Photosyn. Res. 47: 291-292.

Cinco RM, MacInnis JM, and Greenbaum E (1993) The Role of Carbon Dioxide in LightActivated Hydrogen Production by Chlamydomonas reinhardtii. Photosyn. Res. 38: 27-33.

Gaffron H (1960) Energy storage: photosynthesis. In Plant Physiology IB: 4-277.

Gaffron H and Rubin J (1942) Fermentative and photochemical production of hydrogen in algae.

J. Gen. Physiol. 26: 219-240.

Ghirardi ML, Togasaki RK, and Seibert M (1997) Oxygen sensitivity of algal hydrogen production. Appl. Biochem. Biotech., in press.

Gibbs M, Hollaender A, Kok B, Krampitz LO, and San Pietro A (1973) Proceedings of the Workshop on Bio-Solar Conversion, September 5-6, 1973, Betheseda, MD, NSF RANN Grant GI 40253 to Indiana University.

Graves DA, Tevault CV, and Greenbaum E (1989) Control of Photosynthetic Reductant: The Effect of Light and Temperature on Sustained Hydrogen Photoevolution in Chlamydomonas sp. in an Anoxic Carbon Dioxide Containing Atmosphere. Photochem. 
Photobiol. 50: 571-576

Greenbaum E (1977a) The photosynthetic unit size of hydrogen evolution. Science 196: 878-879. Greenbaum E (1977b) The molecular mechanisms of photosynthetic hydrogen and oxygen production. In Biological Solar Energy Production, A. Mitsui, S. Miyachi, A. San Pietro, and S. Tamura, Eds. (Academic Press, New York) pp. 101-107.

Greenbaum E (1979) The turnover times and pool sizes of photosynthetic hydrogen production by green algae. Solar Energy $23: 315-320$.

Greenbaum E (1980) Simultaneous photoproduction of hydrogen and oxygen by photosynthesis. Biotechnol. Bioengin. Symp. 10, 1-13.

Greenbaum E (1982) Photosynthetic hydrogen and oxygen production: kinetic studies. Science 215: 291-293.

Greenbaum E (1988) Energetic efficiency of hydrogen photoevolution by algal water splitting. Biophys. J. 54: 365-368.

Greenbaum E, Lee JW, Blankinship SL, and Tevault CV (1997b) Hydrogen and oxygen production in mutant Fud26 of Chlamydomonas reinhardtii Proceedings of the 1997 U.S. DOE Hydrogen Program Review. May 21-23, 1997, Herndon, VA, in press.

Greenbaum E, Lee JW, Tevault CV, Blankinship SL, and Mets LJ (1995) $\mathrm{CO}_{2}$ Fixation and photoevolution of $\mathrm{H}_{2}$ and $\mathrm{O}_{2}$ in a mutant of Chlamydomonas lacking Photosystem $\mathrm{I}$. Nature 376: 438-441.

Greenbaum E, Lee JW, Tevault CV, Blankinship SL, Mets LJ, and Owens TG (1997a) Photosystem I measurement in mutants B4 and F8 of C. reinhardtii. Science 277: 167 168 , Nature, in press.

Herron HA and Mauzerall D (1972) The development of photosynthesis in a greening mutant of 
Chlorella and an analysis of the light saturation curve. Plant Physiol. 50: 141-148.

Kaltwasser H, Stuart TS, and Gaffron H (1969) Light-Dependent Hydrogen Evolution by

Scenedesmus. Planta (Berlin) 89: 309-322.

Lee JW, Tevault CV, Owens TG, and Greenbaum E (1996) Oxygenic photoautotrophic growth without Photosystem I. Science 273: 364-367.

Lien S and San Pietro A (1975) An Inquiry into Biophotolysis of Water to Produce Hydrogen, NSF RANN report under grant GI 40253 to Indiana University.

Melis A (1989) Spectroscopic methods in photosynthesis: photosystem stoichiometry and chlorophyll antenna size. Phil. Trans. R. Soc. Lond. B 323: 397-409.

Melis A, Murakami A, Nemson JA, Aizawa K, Ohki K, and Fujita Y (1996) Chromatic regulation in Chlamydomonas reinhardtii alters photosystem stoichiometry and improves the quantum efficiency of photosynthesis. Photosyn. Res. 47:253-265.

Melis A, Neidhardt J, Baroli I, and Benemann, JR (1998) Maximizing photosynthetic productivity and light utilization in microalgae by minimizing the light-harvesting chlorophyll antenna size of the photosystems. These proceedings, in press.

Mitsui A, Miyachi S, San Pietro A and Tamura S, Eds. (1977) Biological Solar Energy Production (Academic Press, New York).

Spruit CJP (1958) Simultaneous photoproduction of hydrogen and oxygen by Chlorella. Mededel. Landbouwhogeschool (Wageningen/Nederland) 58:1-17.

Stuart TS and Gaffron H (1972) The mechanism of hydrogen photoproduction by several algae. Planta (Berlin) 106: 91-100.

Stuart TS and Gaffron H (1971) The kinetics of hydrogen photoproduction by adapted Scenedesmus. Planta (Berlin) 100: 228-243. 
Stuart TS and Gaffron H (1971) The kinetics of hydrogen photoproduction by adapted Scenedesmus. Planta (Berlin) 100: 228-243

\section{Figure Legends}

Fig. 1 Schematic illustration of the process of photosynthetic hydrogen and oxygen evolution in green algae. The hydrogenase is synthesized under anaerobic conditions. In the absence of $\mathrm{CO}_{2}$ the natural terminal electron acceptor, photogenerated reductant can be expressed as molecular hydrogen catalyzed the hydrogenase enzyme.

Fig. 2 Schematic illustration of the relationship between photosynthetic antenna size and saturating light intensity. The parameters labeling each curve are the stoichiometric ratios of chlorophyll antenna pigment to photosynthetic reaction center.

Fig. 3 Schematic illustration of the relationship of chlorophyll antenna size, photosynthetic electron transport chains and conversion efficiency.

Fig. 4 The "leaky" Z-scheme model of photosynthesis. 


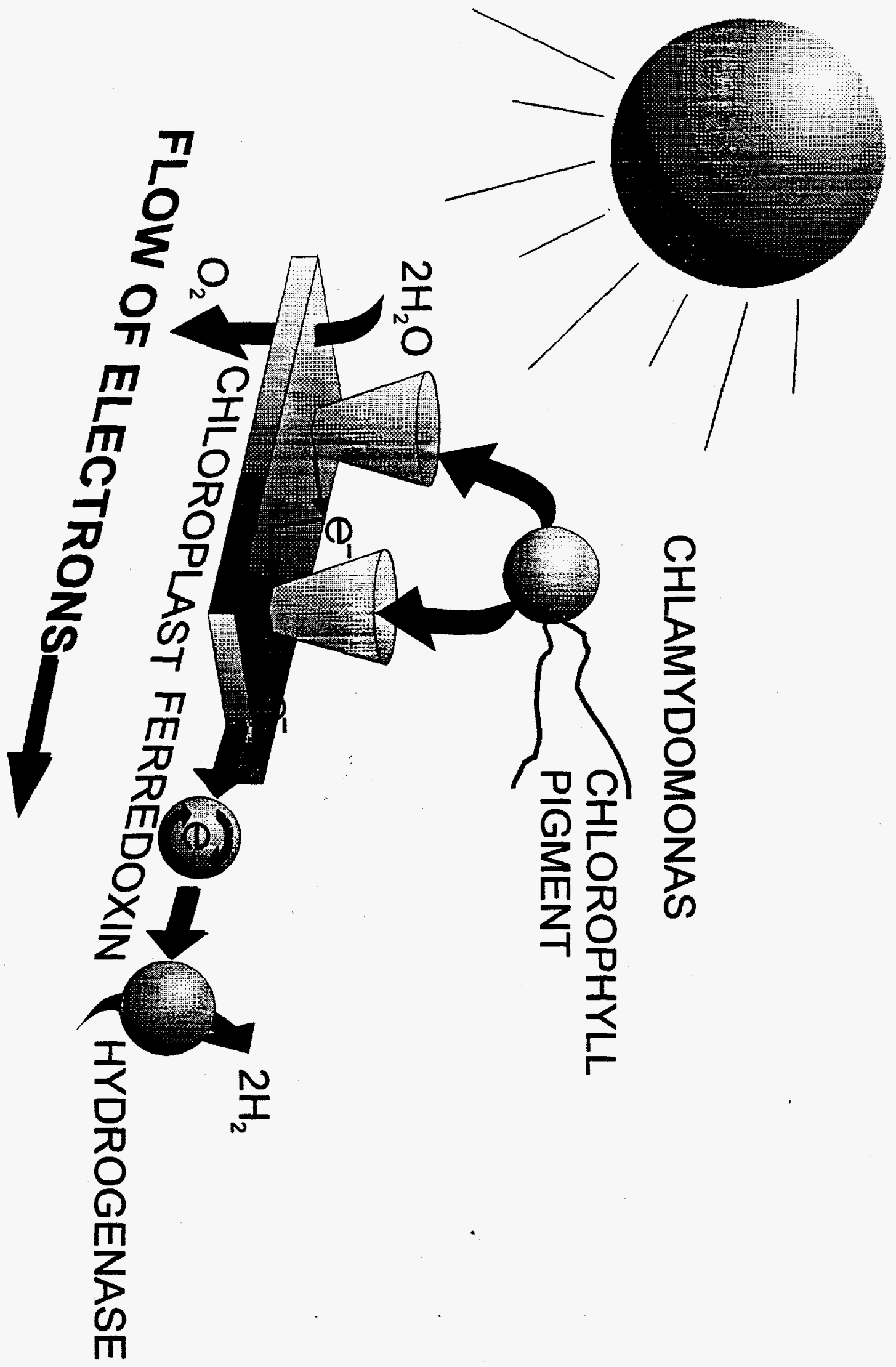




\section{PARAMETRIC CHARACTERIZATION OF THE RATE OF PHOTOSYNTHESIS VS SOLAR RADIATION VARIABLE CHLOROPHYLL: RC RATIOS}

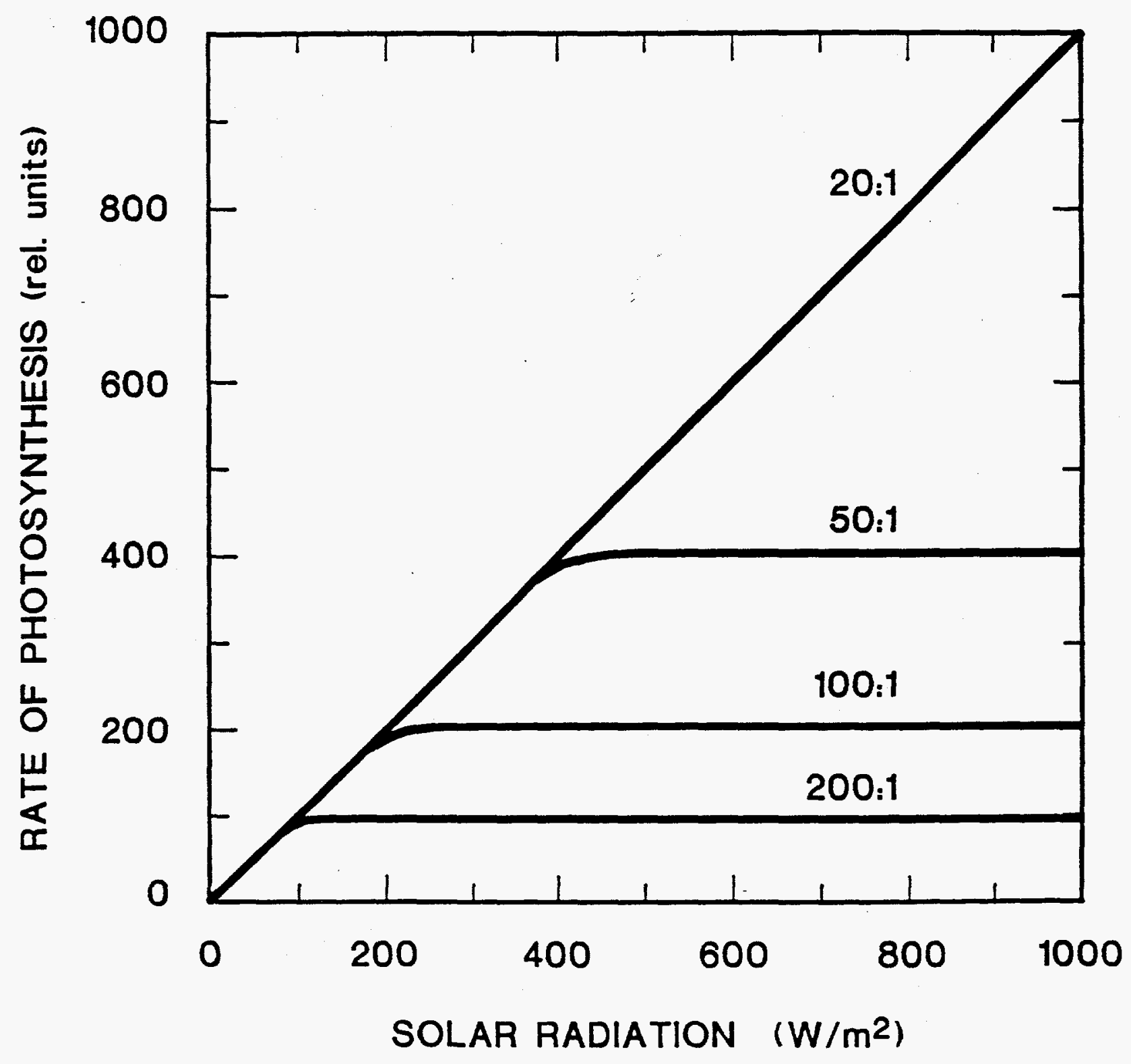




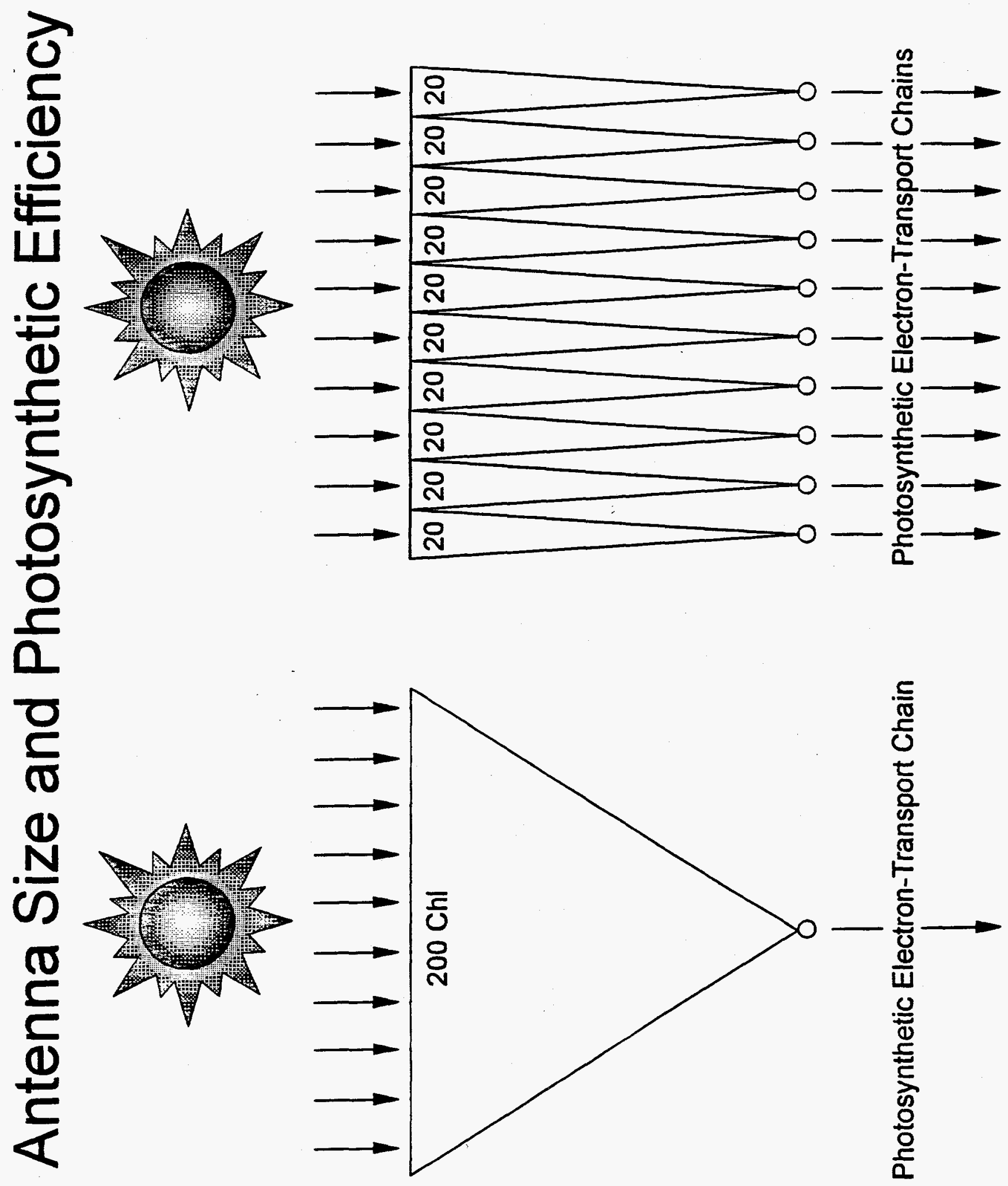




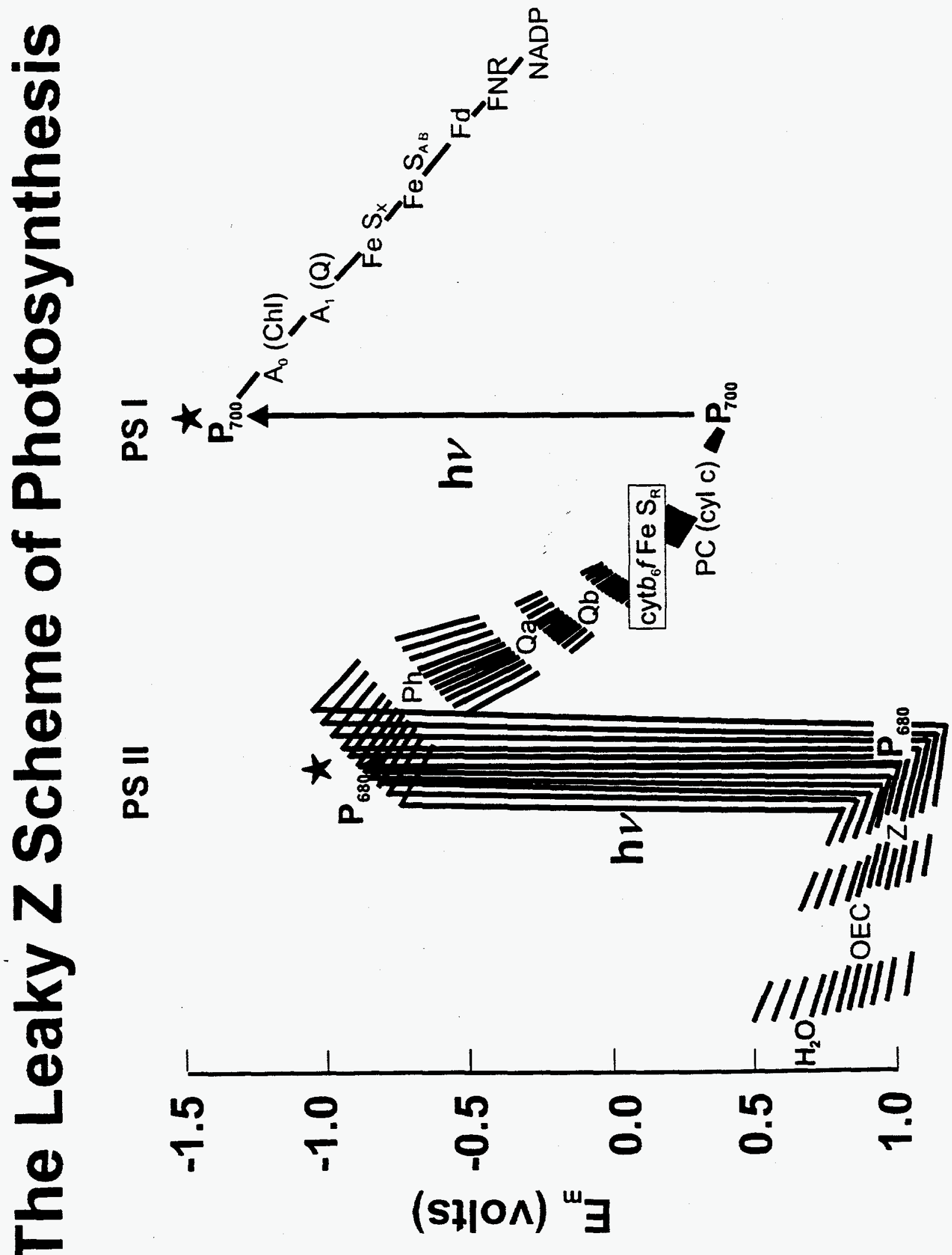

